ARTIGO

Recebido em: $15 / 05 / 2017$

Aceito em: $12 / 04 / 2018$

\title{
Aprendizagem móvel, Competência em Informação e Mediação: interlocução sob a ótica do paradigma social da Ciência da Informação
}

\author{
Mobile learning, Competence in Information and Mediation: \\ interlocution from the perspective of the social paradigm of \\ Information Science
}

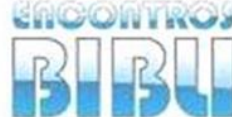

v. 23, n. $52,2018$. p. $34-47$

ISSN 1518-2924
Bárbara Luisa Ferreira CARNEIRO (barbaracarneiro @hotmail.com)* Jefferson Veras NUNES (jefferson.veras@yahoo.com.br)**

Lidia Eugenia CAVALCANTE (cavalcantelidiaeugenia@gmail.com) ${ }^{* * *}$

Maria Giovanna Guedes FARIAS (mgiovannaguedes@gmail.com) ${ }^{* * * *}$

* Mestranda em Ciência da Informação pela Universidade Federal do Ceará.

** Professor do Departamento de Ciências da Informação da Universidade Federal do Ceará e do Programa de Pós-graduação em Ciência da Informação - PPGCI/UFC.

*** Professora do Departamento de Ciências da Informação da Universidade Federal do Ceará e do Programa de Pós-graduação em Ciência da Informação - PPGCI/UFC.

**** Professora do Departamento de Ciências da Informação da Universidade Federal do Ceará e do Programa de Pós-graduação em Ciência da Informação - PPGCI/UFC.

\section{Resumo}

Realiza pesquisa bibliográfica e documental ancorada nos pressupostos teóricos da Ciência da Informação (CI), com ênfase no paradigma social. Aborda a Competência em Informação e a Mediação enquanto conceitos fundamentais à compreensão de fenômenos relacionados ao desenvolvimento e popularização dos recursos tecnológicos. 0 percurso metodológico adotado tem como base a pesquisa exploratória, fazendo uso de levantamento bibliográfico sobre o tema. A partir da análise da literatura, destaca que a Competência em Informação e a mediação, ao aportarem-se no paradigma social contribuem para o desenvolvimento de novas possibilidades teórico-metodológicas no âmbito da CI. Conclui que, tais conceitos, quando atrelados ao contexto da aprendizagem móvel, possibilitam aos indivíduos desenvolverem habilidades relacionadas à busca, recuperação, uso e apropriação da informação, potencializando tanto a construção do conhecimento, como o desenvolvimento de uma postura crítica e reflexiva.

Palavras-chave: Paradigmas da Ciência da Informação. Competência em Informação. Mediação. Aprendizagem móvel.

\section{Abstract}

It performs bibliographic and documentary research anchored in theoretical assumptions of Information Science (IS), with emphasis on the social paradigm. It addresses Information Competence and Mediation as fundamental concepts to the understanding of phenomena related to the development and popularization of technological resources. The methodological course adopted is based on the exploratory research, making use of a bibliographical survey on the subject. From the analysis of the literature, it emphasizes that Information Competence and Mediation, as they contribute to the social paradigm, contribute to the development of new theoretical and methodological possibilities within the scope of IS. It concludes that such concepts, when linked to the context of mobile learning, enable individuals to develop skills related to the search, retrieval, use and appropriation of information, enhancing both the construction of knowledge and the development of a critical and reflexive posture.

Keywords: Paradigms of Information Science. Information literacy. Mediation. Mobile learning. 


\section{INTRODUÇÃO}

A sociedade contemporânea tem se caracterizado pela constituição de novas práticas culturais, bem como por mudanças na organização do tempo e do espaço. E isso se deve, principalmente, ao advento das Tecnologias de Informação e Comunicação (TIC), responsáveis por modificar a dinâmica da vida dos indivíduos. Nesse contexto, a informação desempenha um relevante papel, possibilitando a apropriação e geração de novos conhecimentos.

Juntamente ao desenvolvimento e popularização dos recursos tecnológicos e aos estudos que passaram a introduzir variadas possibilidades teórico-metodológicas para se discutir a informação enquanto fenômeno social, surgiram, no âmbito da Ciência da Informação (CI), diferentes abordagens de aprendizagem, voltadas, por exemplo, à utilização de dispositivos móveis. Tal abordagem pode ser analisada à luz do termo "aprendizagem móvel", o qual diz respeito à conquista de conhecimentos por meio das tecnologias móveis, processo este que pode se realizar independente das coordenadas espaciotemporais.

A pesquisa TIC Domicílios realizada em 2016 pelo Centro Regional de Estudos para o Desenvolvimento da Sociedade da Informação (CETIC) apresenta um crescimento considerável no uso da internet no Brasil, e isso se deve, principalmente, aos dispositivos móveis. Em 2016, o número de casas com conexões móveis chagava a 9,3 milhões, ao passo que, em 2012, esse número era de apenas 5 milhões, ou seja, verifica-se um aumento considerável de $86 \%$. No total, $54 \%$ de todas as casas e $61 \%$ das pessoas com mais de 10 anos de idade possuem acesso a conexões móveis. Entre os usuários pesquisados, 43\% assinalaram usar apenas o celular para navegar na internet, número que era de apenas $20 \%$, em 2014. Com relação ao número de pessoas que usa apenas o computador para acessar a web, o percentual foi de $6 \%$. 0 restante das pessoas acessa tanto pelos computadores quanto pelos dispositivos móveis 1 .

Ainda sobre o crescimento na utilização de tecnologias móveis, de acordo com a $28^{a}$ Pesquisa Anual de Administração e Uso de Tecnologia da Informação nas Empresas, realizada pela Fundação Getúlio Vargas de São Paulo (FGV-SP), a expectativa é que o Brasil tenha atingido, em 2017, pelo menos um smartphone em uso por habitante. Atualmente, o país tem 198 milhões de smartphones sendo utilizados, número que representar um crescimento de $17 \%$ em comparação com os dados da pesquisa realizada no ano de 2016 . De acordo com o estudo, a perspectiva é de que, no próximo ano, o país tenha 236 milhões de consumidores fazendo uso destes aparelhos, representando um aumento de 19\% em relação ao momento atual ${ }^{2}$.

Com base nisso, é possível apontar para a existência de um cenário de múltiplos dispositivos tecnológicos convivendo no dia a dia dos indivíduos, o que indica uma tendência cada vez maior à mobilidade. Nessa perspectiva, busca-se erigir um aporte teórico que subsidie um diálogo reflexivo sobre os paradigmas da Ciência da Informação (CAPURRO, 2003), em especial o paradigma social - que trata a informação levando em conta as ações cotidianas dos indivíduos, destacando o ambiente sociocultural e técnico no qual se encontram inseridos - , relacionando-o aos conceitos de competência em informação e de mediação, bem como à noção de aprendizagem móvel, ressaltando a importância dos indivíduos desenvolverem habilidades relacionadas à busca, recuperação, uso e apropriação de informações.

1 Dados obtidos através do link: https://exame.abril.com.br/negocios/dino/segundo-informacoessmartphones-impulsionam-crescimento-da-internet-no-brasil/. Acesso em 09 dez. 2018.

2 Dados obtidos através do link: http://link.estadao.com.br/noticias/gadget,ate-o-fim-de-2017brasil-tera-um-smartphone-por-habitante-diz-pesquisa-da-fgv,70001744407. Acesso em 25 abr. 2017. 


\section{METODOLOGIA}

Quanto ao caminho metodológico escolhido para a concretização deste artigo, foi realizada uma pesquisa bibliográfica e documental, que, conforme Cavalcante e Bentes Pinto (2015), caracteriza-se como um conjunto de técnicas para se buscar informações e conhecimentos registrados, sejam eles analógicos ou digitais, atendendo a uma necessidade específica. A pesquisa bibliográfica está ligada aos procedimentos técnicos adotados e tem como objetivo viabilizar a compreensão de conceitos teóricos referentes a um tema específico, pertencente a determinado domínio do conhecimento. Nesse sentido, de acordo com Lima e Mioto (2007), a pesquisa bibliográfica possibilita a utilização de dados presentes em referenciais teóricos já existentes, permitindo uma melhor definição do quadro conceitual que envolve o objeto de estudo proposto.

Conforme Marconi e Lakatos (2006, p. 71), a pesquisa bibliográfica não se apresenta como "[...] mera repetição do que foi dito ou escrito sobre certo assunto, mas propicia o exame de um tema sob novo enfoque ou abordagem, chegando a conclusões inovadoras". Para Oliveira (2007, p. 69), "[...] o mais importante para quem faz opção pela pesquisa bibliográfica é ter a certeza de que as fontes a serem pesquisadas já são reconhecidamente do domínio científico", fato que não impede a discussão de temáticas novas, uma vez que serve de suporte a outras pesquisas de cunho teórico e prático.

Considerando que este texto aborda uma temática ainda pouco explorada na Ciência da Informação, especialmente no que tange à relação entre Competência em Informação e Mediação enquanto conceitos fundamentais para o desenvolvimento de novas possibilidades teórico-metodológicas na área, entende-se que ele se configura como uma pesquisa exploratória, uma vez que se mostra como um estudo capaz de auxiliar no desenvolvimento de outras investigações acerca da temática.

Além disso, caracterizando-se como um artigo de revisão, adota-se o roteiro de leitura como a principal técnica para a investigação das premissas desta pesquisa, já que, por meio dele, identifica-se as informações contidas no material selecionado, assim como se observa as relações entre elas com o propósito de analisar a sua consistência. Assim, a leitura realizada foi dividida em quatro etapas, quais sejam: 1) leitura de reconhecimento do material bibliográfico, com o intuito de identificar fontes referentes à temática; 2) leitura exploratória, com o propósito de confirmar a relevância das fontes escolhidas; 3) leitura crítica e interpretativa, destinada ao ordenamento das informações obtidas, de modo a responder aos objetivos da pesquisa; e, por fim, 4) leitura interpretativa, que tem por função relacionar as ideias expressas nas obras selecionadas com o problema para o qual se busca resposta (SALVADOR, 1986; LIMA; MIOTO, 2007).

\section{PARADIGMAS DA CIÊNCIA DA INFORMAÇÃo}

A partir do século XX surgiram várias disciplinas científicas, influenciadas, principalmente, pelo desenvolvimento das Ciências Sociais. Nesse contexto, foi possível testemunhar o aparecimento de uma nova disciplina científica, cujo objetivo pauta-se na compreensão da informação em suas mais variadas esferas. De acordo com Araújo (2003), pode-se dizer que há certo consenso de que a Ciência da Informação não apenas surgiu por volta do século XX, como também é caracterizada pelo desenvolvimento tecnológico e pelas transformações que surgiram no mundo contemporâneo. Assim, o crescimento do volume de informações e de seus registros, especificamente em ciência e tecnologia, foi um dos fatores determinantes para essas mudanças.

Existem muitas divisões em relação às correntes teóricas que compõem a Ciência da Informação; aqui, no entanto, são apresentados três paradigmas dominantes, conforme a visão de Rafael Capurro (2003). São eles: o paradigma físico, o paradigma cognitivo e o paradigma social. Ao apontar a presença de três paradigmas na Ciência da Informação, o autor destaca a importância de se considerar as "relações análogas, equívocas e unívocas entre diversos conceitos de informação e respectivas teorias e campos de aplicação" 
(CAPURRO, 2003, p. 4). Vale destacar que tais paradigmas não se anulam ou se sobrepõem, ao contrário, chamam atenção para determinados problemas informacionais que são percebidos pela área sob diferentes prismas, podendo, inclusive, agregarem-se (BARRETO, 2008).

O primeiro momento da CI baseou-se no gerenciamento da informação, e teve início em um período em que as teorias existentes passaram a não conseguir mais dar conta da quantidade expressiva de informações que estavam surgindo. Os instrumentos disponíveis para organizar as informações não eram suficientes para atender a demanda, o que resultou na criação e definição de métodos que permitissem com que os conteúdos dos documentos fossem representados por meio de indicadores, surgindo, dessa maneira, as linguagens de classificação, indexação e os tesauros (BARRETO, 2008). Esse paradigma construiu-se a partir da teoria da informação de Shannon e Weaver (1975), conhecida também como Teoria Matemática da Comunicação, tomando a informação a partir de um viés estatístico.

0 paradigma físico da informação, de modo geral, defende que há uma mensagem passível de mensuração a qual é transmitida de um emissor a um receptor com a menor interferência possível. De acordo com esta teoria, um determinado sinal elétrico deveria ser enviado de um lado a outro de forma que pudesse ser reconhecido e decodificado. Além disso, o meio pelo qual o sinal se deslocaria deveria estar livre de qualquer ruído que viesse a atrapalhar a transmissão. Outro aspecto que merece ser destacado em relação à teoria de Shannon e Weaver é que o modelo criado por eles se preocupava apenas com o aspecto quantitativo de uma determinada mensagem. Características subjetivas como o conteúdo semântico, ou, ainda, as motivações do produtor da mensagem, são deixadas de lado (COELHO NETTO, 1999).

Um dos autores que se apropria do paradigma físico da informação é Michael Buckland (1991), tido como neodocumentalista e um dos principais responsáveis por levar a obra de Suzanne Briet aos Estados Unidos. 0 autor não só amplia o conceito de documento, analisando-o como algo que está para além do texto impresso, como também identifica três usos corriqueiros para o termo informação, atendo-se principalmente ao último, a saber: "informação como processo", "informação como conhecimento" e "informação como coisa". Através da ideia de "informação como coisa" Buckland (1991) defende que esta é a única forma pela qual a informação pode ser diretamente tratada pelos sistemas de informação. Isto significa que é a partir de sua representação física que a informação pode ser organizada, armazenada e recuperada. Ao optar pela ideia de "informação como coisa", Buckland a concebe como um fenômeno objetivo, dotado de uma existência material, passível de ser registrado.

Entretanto, alguns autores desenvolveram pesquisas que conduzem a uma perspectiva distinta da adotada pelo paradigma físico, chamada por Rafael Capurro de paradigma cognitivo. Dessa maneira, a segunda fase da Ciência da Informação pauta-se na relação entre informação e conhecimento. Nela, a informação tem o objetivo de gerar conhecimento a partir das realidades dos sujeitos que dela se apropriam. Assim, a utilidade da teoria da informação de Shannon e Weaver como sustentação teórica do campo passou a ser contestada. Entre os quadros teóricos existentes, o ponto de vista cognitivo se tornou bastante influente na década de 1980, sendo revisitado e reformulado a partir de 1990 com a ideia de comportamento informacional.

O paradigma cognitivo analisado por Capurro (2003) toma como referência Otlet e La Fontaine e, diferentemente do paradigma físico, inclui a cognição humana no processo, ou seja, trata de investigar como os processos informativos podem ou não transformar os usuários. De acordo com Venâncio e Campos (2006), os estudos pautados numa perspectiva cognitiva foram inspirados, principalmente, pelo "mentalismo" defendido por Brookes (1980), assim como na ideia dos Estados Anômalos do Conhecimento, criada por Belkin 
(1982). Nessa direção, o foco não está necessariamente nos suportes físicos, mas no seu conteúdo e nas formas pelas quais se podem representá-lo cognitivamente.

O paradigma cognitivo aborda também a recuperação da informação e foi bastante influenciado por Karl Popper (1975), que concebia a existência de três mundos do conhecimento. Para o autor, o mais importante é o "mundo dos produtos da mente", por referir-se ao conhecimento objetivo. Brookes embasou seu conceito de informação a partir da teoria de Popper, apontando que cada indivíduo possui uma estrutura de conhecimentos tanto subjetiva como objetiva, que pode ser transformada pela obtenção de novas informações.

Como uma das principais contribuições desta vertente de estudos à Ciência da Informação é interessante mencionar a importância que se passou a atribuir para as necessidades de informações de um usuário, a partir da década de 1980. A necessidade de se buscar informações surge quando há o aludido estado cognitivo anômalo, no qual o conhecimento que o usuário detém passa a não ser suficiente para resolver um determinado problema (SILVA; NUNES, 2014).

Contudo, uma das críticas que frequentemente é direcionada ao paradigma cognitivo se refere ao fato deste considerar o usuário como um sujeito cognoscente livre de condicionamentos sociais e materiais, características estas da vida em sociedade (CAPURRO, 2003). Além disso, nesta perspectiva, não se leva em consideração que a aquisição de informações pode gerar mais questionamentos do que respostas (SILVA; NUNES, 2014). Bernd Frohmann (1992) defende que no que se refere a questões relacionadas à produção, consumo e disseminação de informações, deve-se levar em conta o contexto social no qual o indivíduo está inserido.

Assim, ao contrário de um ponto de vista objetivo, o paradigma social baseia-se em uma vertente subjetiva, buscando compreender o que é a informação e como esta se constrói a partir dos sentidos que são atribuídos a ela pelos indivíduos; sentidos estes que variam conforme suas experiências. Portanto, diferentemente do que defendiam as duas correntes anteriores, tomando a informação como algo que se constrói de modo externo ao indivíduo, ou seja, a priori, no paradigma social é o próprio usuário quem tem o poder de definir o que é ou não informação para si (SILVA; NUNES, 2014).

Rafael Capurro (2003) considera o paradigma cognitivo como "idealista" e "a-social", como se os indivíduos não estivessem envolvidos em uma série de dimensões políticas, econômicas, sociais e culturais. Nessa direção, a informação não é percebida apenas como objeto físico, mas também como algo impalpável. Entendida dessa forma, a informação não deve ser considerada como algo estático; ao contrário, a partir do advento das tecnologias de informação, sua natureza tem se tornado cada vez mais híbrida e volátil.

De acordo com Jesse Shera (1973 apud CAPURRO, 2003), não é possível conhecer os processos intelectuais de uma sociedade somente a partir do estudo do indivíduo, quer dizer, considerando-o de forma isolada. É preciso levar em conta o contexto social no qual este indivíduo está inserido, atentando também para o modo como seus comportamentos e práticas são gerados. Dessa maneira, mesmo que a necessidade de informação se situe em um plano individual, não se pode dissociar o indivíduo de sua cultura.

Como uma de suas implicações pragmáticas, vale assinalar que, de acordo com Hjørland (2003), o foco da Ciência da Informação é estudar as relações entre discursos e documentos no tocante às possíveis expectativas e pontos de acesso de diferentes comunidades de usuários. Portanto, percebe-se que o indivíduo é elemento central na contemporaneidade, o que ajuda a destacar a relevância deste paradigma à Ciência da Informação, sobretudo, porque confere uma nova epistéme. Esta perspectiva torna complexo o entendimento da área sobre a informação, estendendo os limites do campo e contribuindo para a constituição de uma Ciência da Informação transdisciplinar.

Ao citar Cronin (2008), Tabosa, Tavares e Nunes (2016) afirmam que: 
A real importância do aspecto social só foi percebida pela CI apenas por ocasião do terceiro paradigma, em que a informação passou a ser compreendida como um fenômeno social, influenciada por contextos e situações que orientam as ações dos indivíduos e coletividades, influenciando suas necessidades de informação, seus comportamentos de busca e o uso da informação (TABOSA, TAVARES, NUNES, 2016, p. 296).

O paradigma social foi responsável por ampliar a agenda de pesquisas da Ciência da Informação, ressaltando a necessidade de se introduzir novas perspectivas teóricas e metodológicas para tratar a informação enquanto fenômeno social. Assim, concebe o objeto informação numa dimensão subjetiva, a qual possibilita a realização de estudos qualitativos que podem abarcar desde as necessidades de informação e comportamentos de busca, até as práticas relacionadas ao uso, apropriação e mediação da informação. Portanto, no que diz respeito ao paradigma social, reconhece-se os processos cotidianos e as práticas históricosociais enquanto elementos centrais do processo informativo.

Nesse sentido, uma questão que tem desafiado a Ciência da Informação diz respeito à adoção dos dispositivos móveis, principalmente no tocante ao domínio efetivo dos recursos informacionais que marcam este cenário. A combinação entre mobilidade e conectividade promove alterações que se refletem no comportamento informacional dos indivíduos, de modo geral. Porém, de acordo com Mantovani e Dantas (2011), apesar dos dispositivos móveis aumentarem os fluxos informacionais e impulsionarem uma participação ativa dos indivíduos em suas interações com os conteúdos disponíveis, eles também favorecem a busca e uso das informações de maneira superficial, não levando em conta critérios de qualidade e credibilidade.

\section{APRENDIZAGEM MÓVEL}

Conjuntamente ao desenvolvimento e maior utilização dos recursos tecnológicos pelos indivíduos, surgiu uma preocupação por parte dos profissionais da área de educação voltada à busca de meios para incorporar as novas tecnologias no contexto educacional, o que trouxe consequências relevantes para os processos de ensino-aprendizagem. A formação do mediador implica no desenvolvimento de ações e uso da criatividade. Nesse caminho, vale a proposição do aprendizado ao longo da vida que dá ao sujeito a oportunidade de compreender que é necessário aprender sempre (RASTELI; CAVALCANTE, 2013).

Tal preocupação demonstra a necessidade de novas abordagens para o ensino, dentre elas, vale citar aqui, a Blended learning ou b-learning, a Web 2.0 e os ambientes pessoais de aprendizagem, a Massive Open Online Courses (MOOCS) e a aprendizagem móvel ou m-learning, a esta última será dada maior atenção3 ${ }^{3}$.

3 Entende-se por Blended learning ou b-learning a junção de técnicas de aprendizagem virtuais $(e$ learning) e convencionais, associadas às tecnologias interativas. "Cursos híbridos" (ou em inglês Blended learning ou b-learning) é o termo usado para descrever a convergência entre virtual e presencial na educação; a Web 2.0, por sua vez, caracteriza-se pela bidirecionalidade comunicativa. Há nela a potencialidade de promoção da aprendizagem colaborativa, pois os próprios usuários criam conexões e conteúdos, desencadeando uma mudança na forma como as pessoas ascendem às informações nos processos educativos formais ou informais. 0 aprendiz contribui ativamente para a sua própria aprendizagem; com relação aos MOOCs (Massive Open Online Courses), outra novidade na área da educação, estes apresentam-se como "Cursos On-line Abertos de Massa" ou "Cursos Massivos Abertos On-Line". Este tipo de curso caracteriza-se por ser online, gratuito e oferecido a um grande número de pessoas. Em geral não possuem pré-requisitos e também não fornecem certificado gratuitamente, alguns possuem essa opção paga. Os MOOCs geralmente são divulgados em redes sociais, local onde os alunos interagem e discutem acerca de tais cursos (BRITO; VALLS, 2015). 
Prognósticos apontam que os dispositivos móveis representarão $72 \%$ do total de gadgtes e conexões móveis em 2020, número 36\% maior que em 2015, segundo pesquisa realizada em 2016 pela companhia multinacional Cisco Systems. Ainda conforme a pesquisa, os dispositivos inteligentes serão responsáveis por $98 \%$ do tráfego de dados móveis. A proliferação dos telefones móveis está aumentando com tanta rapidez que a previsão é que em 2020 haja mais pessoas com telefones celulares $(5,4$ bilhões) do que eletricidade $(5,3$ bilhões), água encanada (3,5 bilhões) e automóveis ( 2,8 bilhões $)^{4}$.

A partir do potencial de tais dispositivos, acredita-se que estes possam ser usados no processo de ensino-aprendizagem tanto em ambientes formais, como para a educação informal ou continuada. Assim, podem dar suporte ao ambiente presencial, bem como servir a públicos localizados em áreas distantes. Esse fenômeno é chamado de mobile learning, $m$ learning, ou, ainda, aprendizagem móvel.

Aprendizagem móvel refere-se a uma modalidade de ensino contextual que favorece novos tipos de aprendizagem, provenientes da convergência da interação sociocultural dos indivíduos e dos aspectos de usabilidade dos dispositivos móveis que permitem o acesso a uma infinidade de conteúdos, possibilitando uma aprendizagem constante, ou seja, interligando aspectos da aprendizagem formal, não-formal e informal. A seguir, apresenta-se os conceitos destes três termos, segundo dados da UNESCO (2013):

1) Aprendizagem formal refere-se àquela que acontece em instituições de ensino e de formação reconhecidas por autoridades nacionais e que conduz à obtenção de diplomas e qualificações. A aprendizagem formal é estruturada de acordo com a organização educacional a partir de exigências legais.

2) Aprendizagem não-formal é, por sua vez, mais flexível, podendo ser adquirida em adição ou em alternativa à aprendizagem formal. Ela geralmente ocorre fora dos espaços institucionais e está ligada a ações intencionais com assistência do educador.

3) Aprendizagem informal pode ser caracterizada como a aprendizagem que ocorre na vida diária, na família, no trabalho, nas comunidades e através de interesses e demais atividades dos indivíduos. Em alguns casos, o termo "aprendizagem experiencial" é usado para se referir à aprendizagem informal, a qual se concentra no aprendizado a partir da experiência.

Nesse sentido, a aprendizagem com a tecnologia móvel pode ser vista como um exemplo de aprendizagem rizomática. Conforme Sanford et al. (2011), o movimento rizomático refere-se à interconexão de ideias e de exploração sem limites de vários modelos educacionais e tecnológicos, introduzindo a ideia de mistura de aprendizagens. Aprendizagem formal e não formal são aprendizagens intencionais; e, aprendizagem informal, por sua vez, diz respeito à inexistência de intencionalidade, sendo motivada pelo interesse dos indivíduos.

Cada vez mais, no campo do m-learning, a aprendizagem ocorre em ambientes informais, onde as tecnologias móveis estão entrelaçadas à vida cotidiana das pessoas e permitem o desenvolvimento de uma forma de aprendizagem espontânea, movida por necessidades imediatas de informações. As mídias móveis, enquanto ferramentas de aprendizagem informal, implicam diretamente no modo como se compreende o ato de aprender, uma vez que seu contexto educativo envolve práticas da vida real e a experiência cotidiana dos indivíduos com seus próprios dispositivos.

Contudo, de acordo com Ferreira et al (2012), a disponibilidade dessa tecnologia por si só não garante que o seu potencial será utilizado no processo de aprendizagem, nem

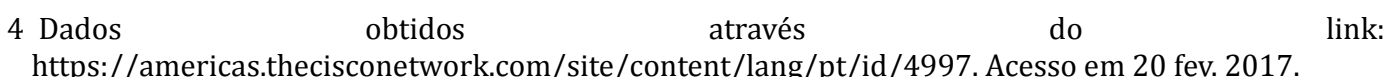


tampouco aceito de forma homogênea por todos. Este processo ainda apresenta-se em fase embrionária, pois há a necessidade da incorporação de outros elementos para além dos tecnológicos.

Conforme assinala Moura (2011), as pessoas se utilizam e se apropriam da tecnologia móvel basicamente como ferramenta comunicacional e de entretenimento, não atentando, muitas vezes, para o potencial desses artefatos enquanto meios de promoção da aprendizagem. Por sua vez, para Meirelles e Tauroco (2005), as atividades de aprendizagem com mobilidade devem ter uma metodologia que leve em conta as especificidades dessas tecnologias, bem como processos sociais, que são parte do ato de aprender.

Ficheman (2008), ao abordar o termo "aprendizagem móvel", afirma que as pesquisas sobre a temática têm migrado seu foco da mobilidade do equipamento para a mobilidade do aprendiz. Segundo o autor, as pesquisas sobre aprendizagem móvel baseiamse, sobretudo, nas mudanças que as tecnologias podem provocar nos aprendizes, bem como de que forma elas podem contribuir com o desenvolvimento de habilidades e experiências. Essa mudança de foco permite ainda a compreensão de diferentes tipos de mobilidade, que interferem na forma como a aprendizagem acontece. São eles: a mobilidade no espaço físico, que se refere à relação do aprendiz com o espaço físico e como este pode contribuir para as experiências de aprendizagem; a mobilidade no espaço social, que se refere a mobilidade do aprendiz entre situações formais e informais de aprendizagem; e, por fim, a mobilidade da tecnologia, ou seja, a forma como o aprendiz utiliza os equipamentos e transita entre eles para a execução de tarefas.

Nesse sentido, a aprendizagem móvel diferencia-se do e-learning 5 , pois possui ferramentas capazes de oferecer maior controle e autonomia sobre o ato de aprender, permitindo que isto ocorra no local, horário e nas condições que o aprendiz considerar mais adequadas, de acordo com suas necessidades e interesses. Contudo, há algumas questões que devem ser levadas em conta e que se referem às limitações técnicas, tais como, por exemplo, a baixa capacidade de armazenamento de dados de alguns modelos de dispositivos móveis, tamanho da tela que pode não ser o mais adequado, necessidade de uso de bateria, além de problemas de software e de interoperabilidade (BRITO; VALLS, 2015).

0 advento dos dispositivos móveis acarretou mudanças de diversas ordens, dentre as quais, torna possível o aprendizado fora dos limites do ambiente educacional tradicional. A aprendizagem mobile faz alusão ao uso de tecnologias móveis em atividades de aprendizagem e no acesso a informações com maior praticidade e velocidade. Tais atividades podem ser realizadas a partir de qualquer lugar e a qualquer hora, trazendo informação e conhecimento para a situação e o lugar onde o ato de aprender acontece, auxiliando na construção da cidadania.

Como apontam Vitorino e Piantola (2011), a cidadania é construída a partir do desenvolvimento e da capacidade de interpretação da realidade, e não apenas por meio do acesso material à informação. Isto significa que não basta somente ter acesso aos recursos informacionais, mas é preciso ainda competência para lidar com eles.

Desse modo, cabe, a partir daqui, observar como os conceitos de competência e mediação da informação podem ser abordados no âmbito de um paradigma social da Ciência da Informação, tomando como ponto de partida as ideias de Almeida Júnior $(2007$; 2008; 2009), Belluzzo (2005; 2008), Dudziak (2003; 2010) e Varela (2006), dentre outros.

50 e-learning pauta-se em duas abordagens, quais sejam, a abordagem tecnológica e a pedagógica. Do ponto de vista tecnológico, está associado e tem como suporte a Internet e os serviços de publicação de informação e de comunicação que esta disponibiliza. Já do ponto de vista pedagógico, implica a existência de um modelo de interação entre professor-aluno, ou mesmo de um modelo de interação aluno-aluno, numa perspectiva colaborativa (GOMES, 2005). 


\section{COMPETÊNCIA EM INFORMAÇÃO E MEDIAÇÃO: conceitos entrelaçados}

A expressão competência em informação surgiu em 1974, nos Estados Unidos, em um relatório intitulado The information service environment relationships and priorities, que descrevia produtos e serviços de instituições privadas e suas relações com as bibliotecas. Esse relatório, de autoria do bibliotecário americano Paul Zurkowski, previa um cenário de mudanças significativas no que diz respeito ao fenômeno informacional, apontando para o início de um movimento em direção à information literacy. No campo da Ciência da informação no Brasil, há certa predominância da tradução do termo information literacy para competência em informação, ou competência informacional, por abranger os principais aspectos relacionados ao seu conceito, representando a habilidade e a capacidade de usar a informação (DUDZIAK, 2003; FARIAS; BELLUZZO, 2012).

Os fundamentos da competência em informação estão ligados ao fazer do bibliotecário, principalmente em situações específicas de usos da biblioteca e de seus recursos informacionais. Todavia, a competência em informação assume, a partir da década de 1980, contornos diferentes, uma vez que passa a priorizar o aprendizado ao longo da vida. Os processos investigativos e a construção de conhecimento constituem parte de todas as ações do bibliotecário, sejam estas ações junto aos sistemas formais ou informais (DUDZIAK, 2001)

De acordo com Varela (2006), para as pessoas manterem-se atualizadas e conseguirem satisfazer as suas necessidades informacionais, é fundamental que tenham domínio do uso de ferramentas tecnológicas e diversos recursos informacionais para a busca, recuperação, avaliação, apropriação e disseminação da informação. Estas ações, por sua vez, são chamadas de competência em informação e compreendem um conjunto de conhecimentos e habilidades que um indivíduo necessita incorporar para lidar, de forma crítica e reflexiva, com os diversos recursos informacionais existentes e que se encontram à sua disposição.

De forma semelhante, Dudziak (2010) compreende a competência em informação (ou literacia informacional) como sendo resultado de um conjunto de conhecimentos, habilidades, atitudes e recursos direcionados a diferentes ações, tais como, a percepção e o reconhecimento da demanda informacional e da atualização constante; a busca de informações em diferentes fontes; a análise, interpretação, avaliação e organização das informações pertinentes e relevantes, observando sua origem e confiabilidade; a preservação da informação, registrando-a e arquivando-a de modo adequado; e, a reutilização da informação em outras situações, para a construção de novos conhecimentos.

A partir do desenvolvimento dos estudos sobre competência em informação, diferentes concepções passaram a fundamentar a temática. As principais, conforme Belluzzo (2005) e Dudziak (2003), são: a) a concepção da informação digital, com ênfase na aprendizagem do uso das tecnologias de informação e comunicação para a busca e recuperação da informação desejada; b) a concepção da informação propriamente dita, que tem destaque nos processos cognitivos para a construção de mapas conceituais e de estratégias de localização da informação; e, por fim, c) a concepção da informação social, que possibilita a inclusão social do indivíduo, voltada ao exercício da cidadania, na qual todos os participantes do processo adquirem aprendizado contínuo.

Além das concepções apresentadas acima, é possível encontrar literatura internacional sobre um conceito diretamente ligado ao de competência em informação, qual seja, o de literacia mediática (LAGE; DIAS, 2011). A literacia mediática aborda, sobretudo, a capacidade de ascender aos media, o que significa compreender e avaliar de modo crítico os diferentes aspectos dos meios de comunicação, atentando para questões como o conteúdo que é veiculado na mídia, os vieses e interesses dos produtores; questões de legalidade; questões de inclusão social, que se configuram como pré-requisito à cidadania ativa e plena; e, a importância da literacia para o desenvolvimento de competências em informação 
(KAMERER, 2013). É interessante ressaltar que as pessoas devem ser educadas em todas as formas de expressão mediadas contemporâneas, dada a dinâmica de uma cultura da convergência, onde gera-se, consome-se, dissemina-se e veicula-se informações a todo instante.

Nessa direção, a literacia mediática pode ser entendida como o acesso às novas tecnologias de informação e à utilização competente e crítica dos seus conteúdos e, mais especificamente, como a capacidade de utilizar autonomamente os diversos media, de compreender e avaliar de modo crítico os diferentes aspectos da informação e dos seus conteúdos, bem como criar e difundir conteúdos midiáticos. Observa-se, além disso, que, perante a multiplicidade de fontes disponíveis, faz-se necessário desenvolver a capacidade de filtrar com exatidão informações dos diversos dados e imagens veiculadas pelos media (LAGE; DIAS, 2011).

Dudziak (2010) defende ainda a convergência entre a competência informacional e a competência midiática. Segundo a autora, esta convergência reúne e fortalece o sujeito aprendiz e é pré-requisito para o êxito da aprendizagem, contribuindo para a conscientização na utilização de informações, a partir da elaboração de estratégias adequadas às diferentes mídias, bem como contribui para o desenvolvimento do pensamento crítico em relação à informação e aos meios de comunicação, possibilitando o pleno exercício da liberdade de expressão e a efetiva cidadania pela apropriação eficaz das ferramentas e recursos informacionais.

Belluzzo (2008) afirma que a competência em informação possibilita intervenções práticas na realidade, as quais podem estar amparadas na mediação. Nesse sentido, cabe recorrer a Almeida Júnior (2009, p. 92), quando este assinala que a mediação envolve uma ação de interferência "realizada pelo profissional da informação, direta ou indireta; consciente ou inconsciente, singular ou plural; individual ou coletiva; que propicia a apropriação da informação que satisfaça, plena ou parcialmente, uma necessidade informacional".

A mediação e a competência em informação aportam-se no paradigma social da Ciência da Informação por possibilitarem o estudo da informação a partir de seu contexto de produção, uso, apropriação e compartilhamento.

Por volta dos anos 1990 os estudos sobre mediação da informação passaram a deslocar a ênfase que recaía sobre o atendimento ao usuário para abarcar todo o fazer do profissional da informação. Para Almeida Júnior (2008, p. 4-5), temos dois tipos de mediação: a mediação explícita da informação, que envolve as atividades que acontecem "[...] nos espaços em que a presença do usuário é inevitável, é condição sine qua non para sua existência, mesmo que tal presença não seja física, como, por exemplo, nos acessos à distância [...].", como acontece nos Serviços de Referência; e a mediação implícita da informação, ocorrendo "[...] nos espaços dos equipamentos informacionais em que as ações são desenvolvidas sem a presença física e imediata dos usuários".

Não raro, identifica-se a mediação como uma "ponte" que permite o relacionamento entre dois pontos. Todavia, segundo o autor, tal imagem é inadequada, uma vez que oferece a ideia de algo estático. 0 autor critica a possibilidade de neutralidade por parte do profissional da informação. Afinal, a informação vai além do aparente, carregando consigo interesses econômicos, políticos e culturais. Contudo, a interferência não deve ser confundida com manipulação, pois, se o profissional tem consciência de que está interferindo, pode ao menos diminuir os riscos e consequências de seu ato (ALMEIDA JÚNIOR, 2009). A informação é mediada para que seja apropriada pelo indivíduo, já que a apropriação "[...] pressupõe uma alteração, uma transformação, uma modificação do conhecimento" (ALMEIDA JUNIOR, 2007, p. 36).

Ao tratar de mediação, Gomes (2010) ressalta que é preciso situá-la como ação vinculada à vida, ao movimento, ao processo de construção de sentidos, tomando como base 
o pensamento de Vygotsky, o qual defende que o ser humano se desenvolve pela interação social. É através de uma ação partilhada que o conhecimento pode ser construído, onde se deve levar em conta tanto a relação dos indivíduos entre si, como com o meio no qual estão inseridos (VYGOTSKY, 1991). Para isso, a mediação da informação é fundamental por se tratar da intervenção humana para apoio a busca de informação, podendo promover a aprendizagem individual e coletiva (KULHTHAU, 1993).

De acordo com Matui (1995), a mediação é o processo de intervenção de elementos sociais e simbólicos enquanto formas de representação da realidade. Para o autor, pode-se identificar os agentes mediadores por sua atuação no sentido de favorecer a interação entre sujeito e objeto do conhecimento, permitindo a apreensão pelo indivíduo dos objetos físicos inseridos, histórica e culturalmente, no contexto das relações simbólicas que permeiam o social.

Dessa forma, a competência em informação se inclui em tal processo justamente por se constituir enquanto atividade que objetiva desenvolver o senso crítico das pessoas em relação à informação. 0 sujeito competente em informação pode identificar a natureza da informação necessária; acessá-la de forma eficaz e eficiente; avaliá-la criticamente; e, incorporá-la em sua base de conhecimento e sistema de valores (FARIAS, 2014). Mediar e desenvolver competências e habilidades relacionadas à busca, recuperação, uso e apropriação da informação são processos que potencializam a construção do conhecimento, bem como proporcionam ao indivíduo avaliar crítica e reflexivamente suas necessidades informacionais.

\section{CONSIDERAÇÕES FINAIS}

Está-se diante de novas formas de construção do conhecimento, nas quais a mobilidade, a tecnologia, a criatividade e a mediação envolvidas neste processo não podem deixar de ser consideradas. Há a necessidade de espaços de aprendizagem onde existam engajamento, imersão e prazer por parte dos envolvidos e a tecnologia digital permite que isso ocorra, avançando para além de um processo de aprendizagem linear.

Frente a esse desafio, destaca-se a necessidade de investigações baseadas em evidências científicas para legitimar as reais contribuições das tecnologias móveis aos processos de ensino-aprendizagem, bem como a exemplificação de sua utilização em espaços educativos diversos. As tecnologias têm oferecido aos indivíduos diferentes recursos informacionais, especialmente no âmbito dos dispositivos móveis. Estes, quando utilizados de modo competente e criativo, ampliam as fontes de informação, dando suporte para metodologias e modos de ensinar e aprender atrativos e inovadores.

Fenômenos relacionados às diferentes formas de aprendizagem contemporâneas desafiam a Ciência da Informação a compreender não apenas processos desencadeados pelas tecnologias, mas chamam a atenção também para a implicação de fatores subjetivos, que apontam para um momento histórico marcado pelo advento da produção, consumo e circulação de informações em massa. Portanto, há a necessidade de se focar em pesquisas que tratem sobre informação levando em conta as ações cotidianas dos indivíduos, destacando o ambiente sociocultural e técnico no qual se encontram inseridos.

É importante ressaltar que o acesso às tecnologias de informação requer dos indivíduos uma utilização competente e crítica dos seus conteúdos, fazendo-se necessário desenvolver a capacidade de filtrar informações obtidas por meio dos diversos dados e imagens veiculadas pelos dispositivos midiáticos. A literacia mediática se mostra, assim, como um importante componente da competência em informação ao possibilitar novas formas de aprendizagem associadas às tecnologias interativas. Ao compreender a existência de uma convergência entre a competência em informação e a literacia mediática, cabe destacar a ideia de que são necessárias estratégias adequadas para utilização da informação 
em diferentes mídias, possibilitando o exercício tanto da liberdade de expressão, como da cidadania através da apropriação das ferramentas e recursos informacionais disponíveis.

Desse modo, conclui-se que o paradigma social defendido por Capurro (2003) tem relação próxima com os conceitos de Competência em Informação e de Mediação, uma vez que, nessa perspectiva, a informação é entendida enquanto fenômeno social, encontrando-se no âmago das práticas histórico-sociais e cotidianas. E mais, tais conceitos, quando atrelados ao contexto da aprendizagem móvel, possibilitam aos indivíduos desenvolverem habilidades relacionadas à busca, recuperação, uso e apropriação da informação, potencializando a construção do conhecimento, assim como o desenvolvimento de uma postura crítica e reflexiva frente à realidade.

\section{REFERÊNCIAS}

ALMEIDA JUNIOR, O. F. de. Leitura, mediação e apropriação da informação. In: SANTOS, J.P. (Org.). A leitura como prática pedagógica na formação do profissional da informação. Rio de Janeiro: Fundação Biblioteca Nacional, 2007. p. 33-45.

Mediação da informação: ampliando o conceito de disseminação. In: VALENTIM, M. L. P. (Org.). Gestão da informação e do conhecimento no âmbito da Ciência da Informação. São Paulo: Poli; Cultura Acadêmica, 2008. p. 41-54.

. Mediação da informação e múltiplas linguagens. Pesquisa Brasileira em Ciência da Informação, Brasília, v. 2, n. 1, p. 89-103, 2009.

ARAÚJO, C. A. A. A ciência da informação como ciência social. Ciência da Informação, v. 32, n. 3, p. 2127, set./dez. 2003.

. Correntes teóricas da Ciência da Informação. Ciência da Informação, v. 38, n.3, p. 192-204, set./dez. 2009.

BARRETO, A. A. Uma quase história da ciência da informação. DataGramaZero, Rio de Janeiro, v. 9, n. 2 , abr. 2008.

BELKIN, N. J. Anomalous states of knowledge as a basis for information retrieval. Canadian Journal of Information Science, Toronto, v. 5, 1982.

BELLUZZO, R. C. B. Como desenvolver a competência em informação (CI): uma mediação integrada entre a biblioteca e a escola. CRB-8 Digital, São Paulo, v. 1, n. 2, p. 11-14, 2008.

. Competências na era digital: desafios tangíveis para bibliotecários e educadores. ETD Educação Temática Digital, Campinas, v. 6, p. 27- 42, 2005.

BRITO, R. G.; VALLS, V. M. Novas formas de aprendizagem e a mediação da informação: competências necessárias aos bibliotecários. Revista Brasileira de Educação em Ciência da Informação (REBECIN), v. 2, p. 3-28, 2015.

BROOKES, B. C. The foundation of Information Science. Journal of the American Society for Information Science, v. 2, p. 125-133, 1981.

BUCKLAND, M. K. Information as a thing. Journal of the American Society for Information Science, v. 42, n. 5, p. 351-360, jun. 1991.

CAMPOS, L. F. de B.; VENÂNCIO, L. S. O objeto de estudo da Ciência da Informação: a morte do indivíduo. Informação \& Informação, Londrina, v. 11, n. 1, jan./jun. 2006.

CAPURRO, R. Epistemologia e ciência da informação. In: ENCONTRO NACIONAL DE PESQUISA EM CIÊNCIA DA INFORMAÇÃ̃O, 5. , Belo Horizonte. 2003. Anais... Belo Horizonte: Associação Nacional de Pesquisa e Pós-Graduação em Ciência da Informação, 2003. 
. O conceito de informação. Perspectivas em Ciência da Informação, Belo Horizonte, v. 12, n. 1, p. 148-207, jan./abr. 2007.

COELHO NETTO, J. T. Semiótica, informação e comunicação. Belo Horizonte: Perspectiva, 1999.

CRONIN, B. The sociological turn in information science. Journal of Information Science, v. 34, 2008.

DUDZIAK, E. A. A information literacy e o papel educacional das bibliotecas. 2001. $187 \mathrm{f}$.

Dissertação (Mestrado em Ciência da Informação e Documentação)- Escola de Comunicação e Artes, Universidade de São Paulo, São Paulo, 2001.

. Information literacy: princípios, filosofia e prática. Ciência da Informação, Brasília, v. 32, n. 1, p. 23-35, jan./abr. 2003.

. Competência informacional e midiática no ensino superior: Desafios e propostas para o Brasil. Prisma.Com, Porto, n.13, p.1-19, 2010.

. Bibliotecário como agente multiplicador da competência informacional e midiática. In: BELLUZZO, R. C. B.; FERES, G. G. Competência em informação: de reflexões às lições aprendidas. São Paulo: FEBAB, 2013. Disponível em: <http://issuu.com/necfci-unb/docs/compet_ncia_em_informa__o_de_re/209>.

FARIAS, G. B. de; BELLUZZO, R. C. B. Reflexões conceituais sobre conhecimento e competência: ensaio para o desenvolvimento de ações de ensino-aprendizagem. In: CAVALCANTE, L. E.; PINTO, V. B.; VIDOTTI, S. A. B. G. (Orgs.). Ciência da Informação e contemporaneidade: tessituras e olhares. Fortaleza: UFC, 2012. p. 89-115.

FARIAS, M. G. G. Análise da produção, implementação e avaliação de um modelo de mediação da informação no contexto de uma comunidade urbana. 2014. 283f. Tese (Doutorado em Ciência da Informação)- Instituto de Ciência da Informação, Universidade Federal da Bahia, Salvador, 2014.

FERREIRA J. B. et al. A disseminação da aprendizagem com mobilidade (M-learning). DataGramaZero, Rio de Janeiro, v.13, n.4, ago. 2012.

FICHEMAN, I. K. Ecossistemas digitais de aprendizagem: autoria, colaboração, imersão e mobilidade. 2008. Tese (Doutorado em Sistemas Eletrônicos)- Escola Politécnica, Universidade de São Paulo, São Paulo, 2008.

FROHMANN, B. The power of images: a discourse analysis of the cognitive viewpoint. Journal of Documentation, v. 48, n. 4, p. 365-286, 1992.

. 0 caráter social, material e público da informação. In: FUJITA, M.; MARTELETO, R.; LARA, M. (Org.). A dimensão epistemológica da ciência da informação e suas interfaces técnicas, políticas e institucionais nos processos de produção, acesso e disseminação da informação. São Paulo: Cultura Acadêmica; Marília: Fundepe, 2008. p. 19-34.

GOMES, H. F. Tendências de pesquisa sobre mediação, circulação e apropriação da informação no Brasil: estudo em periódicos e anais dos ENANCIB (2008-2009). Pesquisa Brasileira em Ciência da Informação, Brasília, v.3, n.1, p.85-99, jan./dez. 2010.

GOMES, M. J. Desafios do e-learning: do conceito às práticas. In: SILVA, B. D.; ALMEIDA, L. S. (Coords.). CONGRESSO GALAICO PORTUGUÊS DE PSICOPEDAGOGIA, 8, Braga. Anais... Braga: CIED, IEP, UM, 2005. p. 66-76.

HJøRLAND, B. Epistemology and the Socio-Cognitive Perspective in Information Science. Journal of the American Society for Information Science and Technology, v. 53, n. 4, p. 257-270, 2003.

KAMERER, D. Media Literacy. Communication Research Trends, v. 32, n. 1, 2013. p. 4-25.

KUHLTHAU, C. C. Seeking meaning: a process approach to library and information services. Norwood: Ablex, 1993.

LAGE, M. O. P.; DIAS, A. M. Literacia informacional e mediática no mundo digital e em contexto de ensino profissional: novo mito ou plano necessário de acção? In: CONGRESSO NACIONAL DE BIBLIOTECÁRIOS, ARQUIVISTAS E DOCUMENTALISTAS, 10, 2010, Lisboa. Anais... Lisboa, 2010. 
LIMA, T. C. S. de; MIOTO, R. C. T. Procedimentos metodológicos na construção do conhecimento científico: a pesquisa bibliográfica. Revista Katálysis, Florianópolis, v. 10, n. esp, p. 37-45, 2007.

MANTOVANI, C.; DANTAS, G. G. C. Os fluxos informacionais nos dispositivos móveis. In: MOURA, M. A. (Org.). Cultura informacional e liderança comunitária. Belo Horizonte: PROEX/UFMG, 2011, p. 121125.

MARCONI, M. de A.; LAKATOS, E. M. Técnicas de pesquisa: planejamento e execução de pesquisas, amostragens e técnicas de pesquisa, elaboração, análise e interpretação dos dados. São Paulo: Atlas, 2006.

Fundamentos de metodologia científica. São Paulo: Atlas, 2010.

MATUI, J. Construtivismo: teoria construtivista sócio-histórica aplicada ao ensino. São Paulo: Moderna, 1995.

MEIRELLES, L. T.; TAROUCO, L. M. R. Framework para aprendizagem com mobilidade. In: SIMPÓSIO BRASILEIRO DE INFORMÁTICA NA EDUCAÇÃO, 2005, Juiz de Fora. Anais... Juiz de Fora, 2005. p. 623633.

MOURA, A. M. C. Apropriação do telemóvel como ferramenta de mediação em mobile learning: estudos de caso em contexto educativo. 2011. 630f. Tese (Doutorado em Educação)- Universidade do Minho, Braga, 2011.

OLIVEIRA, M. M. Como fazer pesquisa qualitativa. Petrópolis: Vozes, 2007.

POPPER, K. R. Conhecimento Objetivo: uma abordagem evolucionária. Belo Horizonte: Editora Itatiaia Limitada, 1975.

RASTELI, A.; CAVALCANTE, L. E. A competência em informação e o bibliotecário mediador da leitura em biblioteca pública. Encontros Bibli: revista eletrônica de biblioteconomia e ciência da informação, Florianópolis, v. 18, n. 36, p. 157-180, jan./abr., 2013.

SANFORD, K. et al. There's no fixed course: rhizomatic learning communities in adolescent videogaming, loading. The Journal of the Canadian Game Studies Association, v. 5, n. 8, p. 50-70, 2011.

SHANNON, C.; WEAVER, W. A teoria matemática da comunicação. São Paulo: Difel, 1975.

SHERA, J. Toward a theory of librarianship and information science. Ciência da Informação, Brasília, v. 2, n. 2, p. 87-97, 1973 .

SILVA, A. W. C.; NUNES, J. V. Práticas informacionais como paradigma: por uma teoria social da informação. In: ENCONTRO NACIONAL DE PESQUISA EM CIÊNCIA DA INFORMAÇÃO, 15. , 2014, Belo Horizonte. Anais... Belo Horizonte: Associação Nacional de Pesquisa e Pós-Graduação em Ciência da Informação, 2014.

TABOSA, H. R.; TAVARES, D. W.; NUNES, J. V. História e epistemologia da Ciência da Informação: abordagem social em foco. Revista Interamericana de Bibliotecología, Medelim, v. 39, n. 3, p. 289300, set./dez. 2016.

UNESCO. Policy guidelines for mobile learning. Paris: United Nations Educational, Scientific and Cultural Organization, 2013.

VARELA, A. V. A explosão informacional e a mediação na construção do conhecimento. In: MIRANDA, A.; SIMEÃO, E. (Org.). Alfabetização digital e acesso ao conhecimento. Brasília: Universidade de Brasília, Departamento de Ciência da Informação e Documentação, 2006. p.15-32.

VITORINO, E. V.; PIANTOLA, D. Dimensões da competência informacional. Ciência da Informação, Brasília, v. 40, n. 1, p. 99-110, jan./abr. 2011.

VYGOTSKY, L. S. A formação social da mente: o desenvolvimento dos processos psicológicos superiores. São Paulo: Martins Fontes, 1991.

Editores do artigo: Enrique Muriel-Torrado e Adilson Luiz Pinto 